American Journal of Agricultural and Biological Sciences 3 (2): 497-501, 2008

ISSN 1557-4989

(C) 2008 Science Publications

\title{
Surveying on Wheat Farmers' Access and Confidence to Information and Communication Channels (ICCs) about Controlling Eurygaster integriceps in Hamedan Province-Iran
}

\author{
${ }^{1}$ Heshmatollah Saadi, ${ }^{1}$ Karim Naderi Mahdei and ${ }^{2}$ Reza Movahedi \\ ${ }^{1}$ Department of Agricultural Extension and Education, College of Agriculture, \\ Bu-Ali Sina University, Hamedan, Iran \\ ${ }^{2}$ Humboldt University of Berlin, College of Agriculture and Horticulture
}

\begin{abstract}
Today, Generation new and various information and knowledge sources need new information and communication channels. The better selection of information and communication channels (ICCs), the more effectiveness of extension programs in agriculture. Surveying on wheat farmers' access to sources of information and communication channels as ICCs about controlling Eurygaster integriceps Puton in Hamedan province of Iran is primary purpose in this research study. The research method used was descriptive-analytic survey (correlation, causative and regression). The population consisted of a sample of wheat farmers $(\mathrm{N}=203)$ on Hamedan province in Iran from 2004 through 2005. Descriptive results of this study showed that all of respondents were male ranged in age from 23 to 83 years. The most important educational need of wheat farmers was identifying new varieties of wheat's resistant to pest. Village extension centers, TV, neighbors/relatives/colleagues, extension agents and radio, were the five important communication channels basis on eligibility to access, respectively. The highest confidence of wheat farmers was toward agricultural research centers, village extension centers, local extension agents, newsletter and TV, respectively.
\end{abstract}

Key words: Wheat farmers, Eurygaster integriceps, Information and Communication Channels (ICCs)

\section{INTRODUCTION}

Today, Generation new and various information and knowledge sources need new information and communication channels. The better selecting information and communication channels or sources, the more effectiveness of extension programs in agriculture ${ }^{[1]}$. Various studies have conducted about sources of information for farmers ${ }^{[2,4,7,9,11,13]}$. Rogers [10] defined the message source as an individual or institution that originates the message and others explained that the message source can be different in each country. Ekoja showed that extension agents, neighbors, other farmers, opinion leaders and organized groups can be sources of information for farmers in Nigeria $^{[5]}$. Nouri interprets that internet and wireless telephone can be as new source of information in Iran ${ }^{[8]}$.Annerose indicated that mobile, internet and electronic publications can be as new source of information for farmers in Senegal ${ }^{[1]}$. According to Ekoja all channels of communication are not preferred equally by farmers. Preference depends largely on how farmers have been sensitized to a particular channel ${ }^{[5]}$. On the other hand Rogers explained that most commonly used channels of communication include mass media (radio and television), print media (pamphlets, brochures, newspapers, labels and magazines) and inter-personal media (seminars, demonstrations, field days, exchange visits and agricultural shows ${ }^{[10]}$.

This study was primarily designed to provide baseline data to extension and other organizations involved in rural development programs for controlling wheat Sunn pest (The Sunn pest Eurygaster integriceps Puton is a very damaging insect pest of wheat and barley in countries of West Asia) in Iran.

Purpose statement: Surveying on wheat farmers' access and confidence toward ICCs about controlling Eurygaster integriceps in Iran is primary purpose in this research study. Some of the secondary objectives accordingly include:

- Describe wheat farmers by personal, farming and social characteristics;

- Identifying amount of wheat farmers' access to sources of information and communication channels (ICCs);

- Specifying a ranking list of sources of information and communication channels (ICCs) basis on farmers' confidence; 
- Determining relationship between independent variables and wheat farmers' access and confidence toward the ICCs; and

- Comparing groups of wheat farmers with their access and confidence toward the ICCs.

\section{MATERIALS AND METHODS}

The research method used was descriptive-analytic survey (correlation, causative and regression). The population statictical consisted of a sample of wheat farmers $(\mathrm{N}=203)$ on Hamedan province in Iran from 2004 through 2005. A questionnaire with 35 forcedchoices and two open-ended questions was utilized. The questionnaire consisted of four sections: personal status of farmers, farming features, assessing questions for proportion of farmer's access to sources of information and communication channels, assessing questions for farmer's confidence toward sources of information and communication channels. Some of the research independent variables were: age, level of education, social status of farmers, background of collaboration in extension courses, size of wheat cultivated land holding, wheat yield per hectare, the extend of use of information and communication channels, awareness sources about spraying deadline for Sunn pest control. Two dependent variables in this research were wheat farmers' access to sources of information and communication channels (ICCs) and wheat farmers' confidence to sources of information and communication channels (ICCs). We have utilized 16 hypotheses for measurement of correlation by Pearson's, rank coefficient Spearman and Kendal and also used 8 hypotheses for the means by two nonparametric tests such as Mann Whitenny and Kruskal Wallis tests. Questionnaire validity which is estimated by Cronbach's Alpha was 83.5.

\section{RESULTS AND DISCUSSION}

Objective one: Describe wheat farmers by personal, farming and social characteristics.

Descriptive results of this study showed that $91 \%$ of farmer respondents were married and $100 \%$ were male. The mean age of respondents was 46.41 years. Wheat farmers who participated in the study ranged in age from 23 to 83 years. About level of education, 30\% of wheat farmers were illiterate, $42.5 \%$ had an elementary education, $17 \%$ had secondary education, $9 \%$ had high school diploma, $1.5 \%$ had post high school education. The average size of wheat cultivated land holding was 30.15 hectare $(51 \%$ rain-fed, $49 \%$ irrigated). The average wheat yield per hectare was 7.8 ton. Wheat farmers were asked to report extends of pollution to Sunn pest: $95 \%$ had Sunn pest problem.

Wheat farmers were asked to indicate their perception ranged from 1 to 5 about educational needs for Sunn pest control. The most important educational needs were ranked respectively: identifying new varieties of wheat's resistant to pest $(\mathrm{M}=3.83, \mathrm{SD}=$ $1.02)$, awareness how to use chemical poisons ( $\mathrm{M}=$ 3.64, $\mathrm{SD}=0.70$ ), mechanical methods for controlling the pest $(\mathrm{M}=3.58, \mathrm{SD}=0.89)$, IPM information about Sunn pest $(\mathrm{M}=3.47, \mathrm{SD}=0.80)$ and wheat's cultivation methods $(\mathrm{M}=3.46, \mathrm{SD}=0.88)$. Wheat farmers were asked to show their sources of information ranged from 0 to 13 about awareness of deadline for Sunn pest control by spraying poison. The most important source for awareness of spraying deadline was ranked respectively: own experience $(\mathrm{N}=$ 203, $\mathrm{P}=51 \%)$, extension agents $(\mathrm{N}=203, \mathrm{P}=28 \%)$, without information $(\mathrm{N}=203, \mathrm{P}=9 \%)$ and plant protection centers $(\mathrm{N}=203, \mathrm{P}=4 \%)$.

The wheat farmers' use of TV per day in hour ranged from 0 to $8(\mathrm{M}=1.25 \mathrm{~h}, \mathrm{SD}=0.88)$. The wheat farmers' use of radio per day in hour ranged from 0 to 6 $(\mathrm{M}=0.21 \mathrm{~h}, \mathrm{SD}=1.08)$.

The wheat farmers' use of book or magazine per day ranged from 0 to $1(\mathrm{M}=0.20, \mathrm{SD}=0.55)$.

The wheat farmers' number of visit with extension agent per month ranged from 0 to $30(\mathrm{M}=2, \mathrm{SD}=$ 3.32). The wheat farmers' number of visit from agriculture service centers per month ranged from 0 to $30(\mathrm{M}=2.78, \mathrm{SD}=3.81)$. The wheat farmers' participation on extension courses ranged from 0 to 1 $(\mathrm{M}=0.31, \mathrm{SD}=0.33)$.

Objective two: Describe wheat farmers' access to the ICCs for Sunn pest control. For achieve to this objective wheat farmers were asked to reveal their perception ranged from 1 to 3 about access to the ICCs for Sunn pest control on 17 items. Results of this study indicated agriculture services centers $(\mathrm{M}=2.94$ out of 3 ) was the highest ranked access and internet ( $\mathrm{M}=1.11$ out of 3) was the lowest ranked access of ICCs. Results also showed TV ( $\mathrm{M}=2.92$ out of 3) was ranked second, friends, neighbors and relatives $(\mathrm{M}=2.91$ out of 3) were ranked third, Seed and fertilizer delivers (M $=2.75$ out of 3 ) were ranked forth and local extension agents ( $\mathrm{M}=2.73$ out of 3$)$ were ranked fifth. On the other hand finding revealed extension houses $(\mathrm{M}=1.13$ out of 3$)$, computer $(M=1.16$ out of 3$)$, agricultural newsletter $(\mathrm{M}=1.25$ out of 3$)$ and agricultural brochures $(\mathrm{M}=1.26$ out of 3$)$ were ranked the last. Table1 shows wheat farmers 'access to the ICCs for puton control by frequency and average ranked. 
Am. J. Agri. \& Biol. Sci., 3 (2): 497-501, 2008

Table1: Wheat farmers 'access to the ICCs for Sunn pest control by frequency and average ranked $(\mathrm{N}=203)$

\begin{tabular}{|c|c|c|c|c|c|c|c|c|c|}
\hline \multirow[b]{2}{*}{ Access to the ICCs } & \multicolumn{2}{|c|}{ Not access } & \multicolumn{2}{|c|}{ limited access } & \multicolumn{2}{|c|}{ Continued access } & \multirow[b]{2}{*}{ Mean } & \multirow[b]{2}{*}{ SD } & \multirow[b]{2}{*}{ Rank } \\
\hline & $\mathrm{F}$ & $\%$ & $\mathrm{~F}$ & $\%$ & $\mathrm{~F}$ & $\%$ & & & \\
\hline Agriculture services center & 3 & 1.5 & 7 & 3.4 & 193 & 95.1 & 2.94 & 0.85 & 1 \\
\hline T.V & 6 & 3.0 & 5 & 2.5 & 191 & 94.6 & 2.92 & 0.56 & 2 \\
\hline Friends, neighbors and relatives & 2 & 1 & 13 & 6.5 & 184 & 92.5 & 2.91 & 0.23 & 3 \\
\hline Seed and fertilizer delivers & 6 & 3 & 39 & 19.2 & 158 & 77.8 & 2.75 & 0.66 & 4 \\
\hline Local extension agents & 18 & 9.1 & 17 & 8.6 & 163 & 82.3 & 2.73 & 1.02 & 5 \\
\hline Radio & 44 & 21.7 & 19 & 9.4 & 140 & 69.0 & 2.47 & 0.44 & 6 \\
\hline Telephone & 27 & 13.4 & 67 & 33.2 & 108 & 53.5 & 2.40 & 0.61 & 7 \\
\hline Video & 94 & 46.3 & 25 & 12.3 & 84 & 41.4 & 1.95 & 1.11 & 8 \\
\hline Agricultural organizations & 113 & 55.9 & 41 & 20.3 & 48 & 23.8 & 1.68 & 0.55 & 9 \\
\hline Agricultural research centers & 146 & 71.9 & 25 & 12.3 & 32 & 15.8 & 1.44 & 0.98 & 10 \\
\hline Rural libraries & 154 & 79.8 & 9 & 4.7 & 30 & 15.5 & 1.36 & 1.21 & 11 \\
\hline Extension workers & 164 & 84.1 & 6 & 3.1 & 25 & 12.8 & 1.29 & 0.83 & 12 \\
\hline Agriculture brochures & 160 & 80.4 & 26 & 13.1 & 13 & 6.5 & 1.26 & 0.89 & 13 \\
\hline Agriculture newsletter and publications & 163 & 80.3 & 29 & 14.3 & 11 & 5.4 & 1.25 & 0.73 & 14 \\
\hline Computer & 184 & 90.6 & 6 & 3.0 & 13 & 6.4 & 1.16 & 0.91 & 15 \\
\hline Extension house & 176 & 92.1 & 5 & 2.6 & 10 & 5.2 & 1.13 & 0.67 & 16 \\
\hline Internet & 187 & 94.6 & 9 & 3.1 & 5 & 2.3 & 1.11 & 1.25 & 17 \\
\hline
\end{tabular}

Not access $=1$, limited access $=2$, continued access $=3$

Table2: Wheat farmers 'confidence toward the ICCs for Sunn pest control by valid percent, standard deviation and ranked average $(\mathrm{N}=203)$

\begin{tabular}{|c|c|c|c|c|c|c|c|c|}
\hline Confidence toward (ICCs) & Very high \% & High $\%$ & Moderate $\%$ & low $\%$ & Very low $\%$ & Mean & SD & Rank \\
\hline Agricultural research centers & 55.4 & 38.5 & 4.6 & --- & 0.5 & 4.46 & 0.73 & 1 \\
\hline Agricultural organizations & 44.9 & 48.6 & 5.6 & 0.5 & --- & 4.37 & 0.64 & 2 \\
\hline Agriculture services center & 42.8 & 53.2 & 3.0 & --- & 1 & 4.36 & 0.64 & 3 \\
\hline Local extension agents & 23.7 & 72.9 & 2.8 & 0.6 & --- & 4.20 & 0.50 & 4 \\
\hline Newsletters & 2.9 & 80.0 & 14.3 & --- & 2.9 & 3.80 & 0.63 & 5 \\
\hline Agriculture magazines & 4.8 & 71.4 & 21.4 & 2.4 & --- & 3.79 & 0.56 & 6 \\
\hline Agriculture brochures & 7.0 & 62.8 & 30.2 & --- & --- & 3.77 & 0.57 & 7 \\
\hline Extension houses & 13 & 69.6 & 4.3 & 4.3 & 8.7 & 3.74 & 1.05 & 8 \\
\hline T.V & 7.1 & 65.2 & 17.7 & 1 & 9.1 & 3.60 & 0.98 & 9 \\
\hline Radio & 10.2 & 61.7 & 13.3 & 5.5 & 9.4 & 3.58 & 1.06 & 10 \\
\hline Seed and fertilizer delivers & 2.0 & 41.0 & 47.2 & 7.2 & 2.6 & 3.33 & 0.75 & 11 \\
\hline Extension workers & 14.3 & 25.0 & 42.9 & 7.1 & 10.7 & 3.25 & 1.14 & 12 \\
\hline Friends, neighbors \& relatives & 0.5 & 13.9 & 75.3 & 5.9 & 4.6 & 3.00 & 0.64 & 13 \\
\hline Computer & --- & 30.0 & 30 & 40 & --- & 2.90 & 0.88 & 14 \\
\hline Telephone & 2.9 & 6.6 & 55.1 & 26.5 & 8.8 & 2.68 & 0.84 & 15 \\
\hline Rural libraries & --- & 11.1 & 52.8 & 19.4 & 16.7 & 2.58 & 0.91 & 16 \\
\hline
\end{tabular}

Very Low $=1$, Low $=2$, Moderate $=3$, High $=4$, Very high $=5$

Objective tree: Describe wheat farmers' confidence toward the ICCs for Sunn pest control.

The third objective of this study was to describe wheat farmers' confidence toward the ICCs for Sunn pest control. Wheat farmers were asked to reveal extent of their perception ranged from 1 to 5 toward the ICCs for Sunn pest control on 16 items. Results of the study indicated agricultural research centers $(\mathrm{M}=4.46$ out of $5, \mathrm{SD}=0.73$ ) was ranked the highest confidence and rural libraries $(\mathrm{M}=2.58$ out of $5, \mathrm{SD}=0.91)$ was ranked the lowest confidence toward ICCs. Findings also showed Agricultural organizations were ranked second $(M=4.37$ out of $5, \mathrm{SD}=0.64)$, Agriculture services center was ranked third ( $\mathrm{M}=4.36$ out of $5, \mathrm{SD}$ $=0.64)$, Local extension agents were ranked forth $(\mathrm{M}=$ 4.20 out of $5, \mathrm{SD}=0.50$ ) and newsletters were ranked fifth $(\mathrm{M}=3.80$ out of $5, \mathrm{SD}=0.63)$. On the other hand finding revealed telephone $(\mathrm{M}=2.68$ out of $5, \mathrm{SD}=$ $0.84)$, computer $(\mathrm{M}=2.90$ out of $5, \mathrm{SD}=0.88)$, friends, neighbors and relatives $(\mathrm{M}=3.00$ out of $5, \mathrm{SD}=0.64)$ were ranked the last. Table 2 illustrates wheat farmers' confidence toward the ICCs for Sunn pest control by valid percent, standard deviation and ranked average.

Objective four: Determine relationship between independent variables and wheat farmers' access and confidence to the ICCs. The relationships between the variables of wheat yield per hectare, size of wheat cultivated land holding, education level, social status were significantly correlative and positively linked both with their access to ICCs and confidence toward the ICCs. Relationship between age and wheat farmers' access and confidence to the ICCs was significantly correlative and negative (Table 3 ). 
Am. J. Agri. \& Biol. Sci., 3 (2): 497-501, 2008

Table 3: Determine relationship between independent variables and farmers' access and confidence to the ICCs

\begin{tabular}{lllll}
\hline Independent variable & Dependent variable & Correlation coefficient & $\mathrm{R}$ & Sig. \\
\hline Age & Access to ICCs & Spearman & $0.233-$ & $0.001^{* *}$ \\
Size of wheat cultivated land holding & Access to ICCs & Spearman & 0.475 & $0.000^{* *}$ \\
Wheat yield per hectare & Access to ICCs & Spearman & 0.453 & $0.000^{* *}$ \\
Education level & Access to ICCs & Kendal tau & 0.432 & $0.000^{* *}$ \\
Social status & Access to ICCs & Kendal tau & 0.563 & $0.000^{* *}$ \\
Age & Confidence to ICCs & Spearman & $0.243-$ & $0.000^{* *}$ \\
Education level & Confidence to ICCs & Kendal tau & 0.444 & $0.000^{* *}$ \\
Social status & Confidence to ICCs & Kendal tau & 0.534 & $0.000^{* *}$ \\
Size of wheat cultivated land holding & Confidence to ICCs & Spearman & 0.248 & $0.000^{* *}$ \\
Wheat yield per hectare & Confidence to ICCs & Spearman & 0.403 & $0.000^{* *}$ \\
\hline
\end{tabular}

Table 4: Compare groups of wheat farmers with their access and confidence to the ICCs

\begin{tabular}{lllll}
\hline Grouping variable & Dependent variable & Test & t & Sig. \\
\hline Education level & Access to ICC & Kruskal Wallis & 52.190 & $0.000^{* *}$ \\
Social status & Access to ICC & KruskalWallis & 13.492 & $0.01^{* *}$ \\
Participation on extension courses & Access to ICC & Mann Whitenny & 22.54 & $0.000^{* *}$ \\
Education level & Confidence to ICC & Kruskal Wallis & 56.512 & $0.000^{* *}$ \\
Social status & Confidence to ICC & Kruskal Wallis & 12.778 & $0.02^{*}$ \\
Participation on extension courses & Confidence to ICC & Mann Whitenny & 29.45 & 0.000 \\
\hline$* 00.05 * * ;<0.01$ & & &
\end{tabular}

${ }^{*} \mathrm{p}<0.05{ }^{* *} \mathrm{p}<0.01$

Objective five: Compare groups of wheat farmers with their access and confidence to the ICCs. The Mann Whitenny test used for comparing two groups of wheat farmers those who participated on extension courses and those who did not. In this part of the study, the Mann Whiney nonparametric test showed that there was significant difference between the two target wheat farmers concerning both the access to ICCs and the confidence toward the ICCs for Sunn pest control. Among the averages of the variables of education level, social status, wheat farmers' access to the ICCs and farmers' confidence toward the ICCs significant differences are exposed when the groups of wheat farmers are compared with each other (Table 4).

\section{CONCLUSION}

Based on the finding of this study, the following conclusion was drawn; In describing features of wheat farmers, it was found that the majority of wheat farmers were marital and $100 \%$ were male. Wheat farmers who involved in the study were no young. About level of education among farmers respondents' majority of them had low level of education (elementary or secondary education) or illiterate. The average size of wheat cultivated land holding was 30.15 hectare. Nearly, all wheat farmers had problem for Sunn pest control in their farms. The most important educational need of wheat farmers was identifying new varieties of wheat's resistant to Sunn pest. After that awareness of how to use chemical poisons, mechanical methods for controlling the pest, IPM information about Sunn pest and wheat's cultivation appropriate methods were ranked respectively.

Village extension centers, TV, neighbors, friends and relatives, extension agents and radio were the five important ICCs basis on eligibility to access respectively. On the other hand, internet, computer and extension houses were ranked the lowest ICCs basis on eligibility to access.

The most confidence of wheat farmers was toward agricultural research centers, village extension centers, local extension agents, newsletter and TV, respectively. The less confidence of wheat farmers was toward rural libraries, telephone and computer, respectively.

About awareness of deadline for Sunn pest control by spraying poison, TV and radio programs hadn't any information for wheat farmers about Sunn pest control in the area of this study. Regardless high access and confidence of wheat farmers toward TV programs and village extension centers the recommendation can be made that Agriculture Organization of Hamedan in Iran can provide new television programs for controlling Sunn pest and show at agricultural extension centers. Moreover, agricultural planners can make newsletter for wheat farmers for Sunn pest control by help of agriculture researchers, extension agents and other confident sources.

In determining relationships between independent variables and wheat farmers' access to ICCs for Sunn pest control, a significant relationship were found between the wheat farmers which were younger, had higher size of wheat cultivated land holding, were more educated, had higher yield per hectare and had higher 
social status. Therefore, the recommendation can be made that the Extension Organizations of Iran can use this information in order to conduct new activities and programs for other wheat farmers about Sunn pest control.

In addition, a significant relationship were found between the wheat farmers' confidence toward the ICCs and the wheat farmers which were younger, were more educated ,had higher social status, had higher size of wheat cultivated land holding and had higher wheat yield. Therefore, it is recommended for future plans about Sunn pest control in the wheat farmers' characteristics include age, education level, social status, size of cultivated land holding and wheat yield per hectare should be taken in to consideration.

In comparing the two groups of farmers (involved and not involved in extension courses), it was found that there was significant difference between these groups of farmers and two dependent variables, both wheat farmers' access to ICCs and wheat farmers' confidence toward ICCs for Sunn pest control. Therefore, Agricultural Training Centers and the Ministry of Agriculture should develop and deliver programs to encourage more farmers involve extension courses.

Results of other means comparing indicated that the means of the variables education level and social status there were significant difference between these groups of farmers and two dependent variables, both wheat farmers' access to ICCs and wheat farmers' confidence toward ICCs for puton control.

In educational importance, the findings of the study may be used to improve Agricultural extension programs offered for controlling Sunn pest in Iran. Extension programming and approaches and linkage activities may be guided by the findings of the study. Preparation of wheat farmers in village extension centers or related institutions may be adapted based on suggestions compiled. In turn, over time, this research can provide baseline data for extension and other organizations involved in dissemination of recommended programs and practices of pest management and controlling Wheat Sunn pest in order to increase wheat productivity.

\section{REFERENCES}

1. Annerose, D., 2003. Mobile telephone and internet linkages. Proceeding of ICC,s-transforming agriculture extension? CTA,s observatory on ICC,s. 6th consultative Expert Meeting. Wageningen, 23-25 Sep. 2003.
2. Arokoyo, T., 2003. ICC's for agriculture extension transformation. Proceeding of ICT's-transforming agriculture extension? CTA,s observatory on ICC,s. 6 th consultative Expert Meeting. Wageningen, 23-25 Sep. 2003.

3. Benor, D. \& Q. Harison 1986. Agricultural extension. World bank. Washington DC. USA.

4. Chizari, M. and G. Dinpanah, 2005. An investigation of effective factors involved in perception of wheat farmers regarding on-farm demonstration in esfahan township, Iran. Proceedings of the 21st Annual Conference on AIAEE. San Antonio, TX 2005.

5. Ekoja, I. 2003. Farmer's Access to agricultural information in Nigeria. Bulletin Of The American Society For Information Science And Technology, Augst /Sep., pp: 21- 23.

6. Escalada, M. \& Heng K. L., 1999. Farmers Testing Rules of Thumb in Integrated Pest Management. IDRC publication. Canada.

7. Maddox, S.J. and RD. Mustain, 2003. Agriculture information preferences of North farmers. Southern Association of Agricultural Scientists Agriculture Communications Section Mobile, Alabama.

8. Nouri, M., 2003. ICT and rural poverty. Proceeding on role of ICCs on rural areas. University of Science and Industry. Tehran, Iran. In Persian.

9. Prakasha, K., 2003. ICT,s transforming agriculture extension? Proceeding of ICT,s-transforming agriculture extension? CTA,s observatory on ICT,s. 6 th consultative Expert Meeting. Wageningen, 23-25 Sep., 2003.

10. Rogers, E., 1995. Diffusion of Innovations. 4th (Ed.). NY: The Free Press. New York.

11. Saadi, H., 1998. Study on factors affecting on farmers participation encouragement for sunn pest control by IPM.Unpublished M.Sc Thesis. University of Tehran.Iran.In Persian.

12. Stevens, S.C., 1991. Enhanced media use. J. Extension., Vol. 29, N. 1. online: www.goe.org/joe/1991 spring/ent.html

13. Turral, A., Noojipady, P, 2002. Understanding the communication context in teso and lango farming system: The Agricultural Information Scoping Study. NARO/ DFID (Depatment for International Development. Ugand. 